\title{
When does a reproducing female viper (Vipera aspis) 'decide' on her litter size?
}

\author{
Olivier Lourdais, Xavier Bonnet, Richard Shine and Emily N. Taylor
}

\begin{abstract}
Some organisms rely on stored energy to fuel reproductive expenditure (capital breeders) whereas others use energy gained during the reproductive bout itself (income breeders). Most species occupy intermediate positions on this continuum, but few experimental data are available on the timescale over which food intake can affect fecundity. Mark-recapture studies of freeranging female aspic vipers Vipera aspis have suggested that reproductive output relies not only on the energy in fat bodies accumulated in previous years, but also on food intake immediately before ovulation. A simple experiment was conducted to test this hypothesis, maintaining female snakes in captivity throughout the vitellogenic period and controlling their food intake. The energy input of a female strongly influenced the amount of mass that she gained and the number of ova that she ovulated. Multiple regression showed that litter size in these snakes was affected both by maternal body condition in early spring (an indicator of foraging success over previous years) and by food intake in the spring before ovulation. Our experimental data thus reinforce the results of descriptive studies on free-ranging snakes, and emphasize the flexibility of energy allocation patterns among vipers. Reproducing female vipers may combine energy from 'capital' and 'income' to maximize their litter sizes in the face of fluctuating levels of prey abundance.
\end{abstract}

\section{INTRODUCTION}

Reproduction requires a considerable expenditure of energy, especially in female organisms that produce large clutches or litters relative to their own body mass. Because food availability fluctuates through time for many species, coupling energy acquisition (feeding) with expenditure (reproduction) is not a trivial problem. The notion of 'capital' vs 'income' breeding offers a useful conceptual framework in which to explore such issues (Drent \& Daan, 1980). Capital breeders gather the energy to fuel reproduction long before the actual reproductive event, whereas income breeders simultaneously gain and expend energy. However, these definitions probably describe the extremes of a continuum. Most kinds of organisms probably depend to some degree on both kinds of resources to support reproductive expenditure. Indeed, different facets of reproductive output within the same

reproductive bout by a single female (such as offspring size vs number) may depend upon different timescales of energy acquisition (Bonnet, Naulleau, Shine et al., 2001).

Squamate reptiles provide good models for studies on this topic, because they display a diversity in systems of energy allocation. Some of the most extreme examples of capital breeding systems are found among viperid snakes, with the aspic viper Vipera aspis perhaps the most intensively studied capital breeder (Saint Girons, 1949, 1957a,b; Saint Girons \& Duguy, 1992; Bonnet, 1996; Bonnet, Naulleau, Lourdais et al., 1999; Naulleau et al., 1999; Bonnet, Naulleau, Shine et al., 2000, 2001; Bonnet, Naulleau \& Lourdais, 2001). Female vipers typically reproduce only once every 2-3 years and sometimes less often (Saint Girons \& Naulleau, 1981). They delay reproduction until they attain a threshold value for body condition (Naulleau \& Bonnet, 1996), and females can reproduce successfully even if they do not feed during the entire year in which the litter is produced 
(i.e. throughout vitellogenesis plus gestation). Thus, 'capital' stored before reproduction can support the entire reproductive effort of female aspic vipers. None the less, field data indicate that female vipers often feed during vitellogenesis, and suggest that food acquired at this time can influence some components of reproductive output (Bonnet, Naulleau, Shine et al., 2001; Lourdais et al., in press). These results suggest flexibility in the system of energy allocation, whereby food intake in the current year, as well as longterm storage of energy gained during previous years, can influence the reproductive output of a female.

This scenario concerning the sources of energy for litter production in aspic vipers is, however, based largely on descriptive studies of free-ranging snakes. In these studies, maternal feeding rates have been inferred from maternal mass gain (Bonnet, Naulleau, Shine et al., 2001). Although logic and indirect evidence support the assumption that these two traits are linked, it remains possible that other factors (such as maternal disease or metabolic expenditure) could also modify rates of gain in body mass. If so, correlations between mass gain and reproductive output might reflect such additional factors, rather than a straightforward effect of enhanced feeding rates on litter sizes. Experimental manipulation of food supplies offers a direct and powerful approach to resolving such uncertainties (Ford \& Seigel, 1989; Seigel \& Ford, 1991, 1992; Gregory \& Skebo, 1998). To investigate the relative influences ofthe initial body stores and subsequent energy intake during vitellogenesis on the reproductive output of female vipers, they were maintained in captivity, their rates of prey consumption directly modified, and the effects of this manipulation on the numbers of offspring that they produced were examined.

\section{MATERIAL AND METHODS \\ Study species}

The aspic viper is a small viviparous snake that is abundant in central western France. In this area, females typically reproduce on a less-than-annual schedule (Saint Girons, 1957a,b; Bonnet \& Naulleau, 1996; Naulleau \& Bonnet, 1996; Naulleau et al., 1999). In reproductive females, the recruitment of ovarian follicles is controlled by endocrine factors at the onset of vitellogenesis in March (Bonnet, Naulleau \& Mauget, 1994). After this initial phase, follicular atresia (i.e. death of ovarian follicles before ovulation; M'endez-De la Cruz, Guillette \& VillagranSanta Cruz, 1993) is the proximate factor controlling litter size (Saint Girons, 1957b; Saint Girons \& Naulleau, 1981). That is, females initially begin to enlarge more follicles than they eventually ovulate, and hence are potentially able to adjust their eventual (ovulated) litter size depending on the conditions that they experience before ovulation. Ovulation occurs during the first 2 weeks of June (Naulleau, 1981), and parturition occurs 2-3 months later, from late August to late September.

\section{Capture and housing}

A total of 108 snakes (48 males and 60 females) was captured in spring 2000 in 3 adjacent localities in West-central France (Château d'Olonnes, Les Sables d'Olonnes and Rochefort). The snakes were collected from late February to mid-April, when they first emerged to bask after the winter hibernation period. Individuals were given identification marks by scale-clipping, and were measured (snout-vent length, SVL $\pm 0.5 \mathrm{~cm}$ ) and weighed $( \pm 0.1 \mathrm{~g})$. Mating occurred in captivity, with each female given a 10-day period of contact with numerous males in an indoor enclosure $(2.5 \times 1.5$ $\mathrm{m}$ ) with a heat source and water. Copulation was frequently observed in this enclosure. After mating (late March), the snakes were examined by abdominal palpation to detect vitellogenic follicles. This procedure revealed that 39 females were reproductive and 21 were non-reproductive.

The 39 vitellogenic females were placed in 8 outdoor enclosures $(5 \times 3 \mathrm{~m}$, mean density 5 snakes/enclosure) recreating the natural habitat and exposed to the climatic conditions of the field research station of Chiz'e (For ${ }^{\wedge}$ et de Chiz'e, Deux-S'evres, $46^{\circ} 07^{\prime} \mathrm{N}, 00^{\circ} 25^{\prime} \mathrm{W}$ ). The enclosures were 
located side by side and had the same orientation and exposure to sunlight. Each enclosure was equipped with the same number of external dens to serve as hiding-places. Water was provided ad libitum and vegetation (mainly annual grasses, Poacae) was kept high $(20-40 \mathrm{~cm})$ to provide shade and shelter.

\section{Experimental design}

To examine the effects of absolute energy intake during vitellogenesis on subsequent litter sizes, the 39 females were randomly allocated to 1 of 2 diet treatments:

(1) high-intake group ( $n=19$, enclosures 1 to 4 ): 1 large mouse (mean mass $25 \pm 5 \mathrm{~g}$ ) per snake per feeding in each enclosure, provided on 4 occasions (every 2 weeks from mid-April to early June);

(2) low-intake group ( $n=20$, enclosures 5 to 8 ): 1 small mouse (14 $\pm 4 \mathrm{~g}$ ) per snake per enclosure, offered on 2 occasions only (mid-April and mid-May).

Snakes of both treatment groups were fed by placing recently killed mice close to their dens, early in the afternoon when climatic conditions were favourable. On each feeding occasion the mass of prey offered was the same $( \pm 1 \mathrm{~g})$ for each replicate enclosure within each treatment. This method allowed us to calculate the total mass of prey consumed $(\mathrm{g})$ for each snake during the experiment. Uneaten prey items were removed the next morning. Prey consumption was recorded by direct observation of feeding, or by less direct means if feeding was not observed (by palpation of mice inside the snake and by increase in body mass).

Snakes were weighed 3 times during the study: early vitellogenesis (early April), midvitellogenesis (mid-May), and close to the time of ovulation (mid-June). Enlarged ovarian follicles were counted by palpation (Fitch, 1987) at mid-vitellogenesis (mid-May) and ovulation (mid-June). This method enables us to detect objects as small as $2 \mathrm{~g}$ (Bonnet, Naulleau, Shine et al., 2001). One female from the low-intake group was killed by a feral cat in early June, and hence data from this individual were not used in most of our analyses.

Our 2 treatment groups differed both in prey size and number in order to mimic the natural situation where snakes may sometimes encounter relatively few, small prey and in other years may encounter prey items that are larger and also more abundant. Thus, the treatments were designed to span the normal range of variation in food supply in terms of both prey size and prey number. Feeding frequency and relative prey sizes are important parameters of snake biology that may influence conversion efficiency (Secor \& Diamonds, 1995). However, the aim of our experiment was simply to modify the level of energy available for follicular growth and thus, the important concern was to generate variations in feeding opportunities comparable to annual variations in food consumption that occur in the field (Lourdais et al., in press).

\section{Statistics}

Data were analysed using Statistica 5.1. To provide an index of body condition (mass relative to length), residual values were calculated from the regression of log-transformed body mass against log-transformed body length (Jayne \& Bennett, 1990). SVLs of the 2 groups of females were compared at the beginning of the experiment in terms of size-frequency distributions as well as mean values. To do so, the data for SVL were standardized $(Z=(X-$ mean value $) / S D)$ so that the distribution had a mean of 0 and standard deviation (SD) of 1 . Three size classes were identified: small $(Z<-0.43)$, medium $(-0.43<Z<0.43)$, and large $(Z>0.43)$ (Marti, 1990). Additionally, a repeated measures ANOVA was conducted to test the effect of treatment on mass change over time.

\section{RESULTS}




\section{The 'decision' to reproduce}

When measured and weighed at the beginning of the study, the females that eventually proceeded to reproduce had a higher body condition index than those that did not enlarge follicles (ANOVA, F1,59 = 45.02, $P<0.00001$; see Fig. 1 ).

Reproductive females in the two food-intake groups did not differ in mean body mass (ANOVA, $F 1,38=0.66, P=0.42$ ), mean SVL (ANOVA, $F 1,38=0.50, P=0.48$ ), or initial body condition (ANOVA, $F 1,38=0.25, P=0.62$ ). The two diet groups were also similar in terms of size-frequency distributions $\left(\chi^{2}=0.025\right.$, d.f. $\left.=2, P=0.98\right)$. For 37 of the 39 reproductive females, ovarian follicles were detected each time that the snakes were palpated. For the remaining two animals, however (one in each diet treatment), palpation in mid-vitellogenesis revealed no detectable eggs. Thus, these animals commenced vitellogenesis but terminated the process before ovulation. These individuals were in lower body condition (residual values $<-0.14$ ) than were the other females belonging to the same size class at the onset of the experiment (residual values >-0.07). Also, neither of these snakes ate the first prey item that they were offered. After deleting these two cancellations, females in the two treatments still did not differ significantly in mean body mass $(P=$ $0.4)$, mean SVL $(P=0.43)$ or more importantly, body condition at the beginning of the experiment $(P$ $=0.69$ ).

\section{Food intake and changes in body mass}

Among the 19 individuals of the low-intake group, 11 females ate one prey item and eight females ate two prey items. Among the 17 females of the high-intake group, four females consumed only one mouse, seven females consumed two mice and six females ate three mice. Unsurprisingly, the total amount ofprey ingested (g) differed significantly between the two groups (Kruskal- Wallis test, $H(1, n=37)=15.4, P=0.0001)$, with mean values ( \pm SD) of $49 \pm 19$ of prey consumed by females in the high-intake group compared to $22 \pm 7 \mathrm{~g}$ for the low-intake group. The variance in food intake was also higher for the high food group $\left(\chi^{2}=0.88\right.$, d.f. $\left.=1, P<0.0001\right)$, reflecting the higher number of feeding opportunities within this group.

Data were pooled from the two groups to examine the relationship between absolute food intake and subsequent changes in body mass. The two variables were significantly correlated $(r=$ $0.89, r^{2}=0.79, n=36, F 1,35=89.79, P<0.0001$; see Fig. 2 ), with energy intake explaining $79 \%$ of the observed variance in mass gain. Food intake was not related to female SVL $(r=0.22 ; n=36, F 1,35=$ $1.76, P=0.20)$.

The difference in average food consumption between the two treatments generated significant differences in the amount of mass gained by females. The increment in mass midway through vitellogenesis was greater for the high-intake group (ANCOVA using mass gain as dependent variable, treatment as factor and initial body mass as covariate, $F 1,34=4.29, P=0.046)$. The magnitude of this difference was enhanced by the time of ovulation $(F 1,33=8.00, P=0.007)$.

The influence of feeding treatment on change in maternal body mass was examined with a repeated measure ANOVA. Using SVL-adjusted body mass as the dependent variable, treatment as factor and the three consecutive records of masses as repeated measures, revealed a significant interaction (Wilk's lambda= $0.75, F 3,29=3.18, P=0.038$ ). The mass gain was significantly more marked in the high-intake group (treatment effect, $F 2,62=5.77, P<0.005$; see Fig. 3 ).

\section{Determinants of fecundity}

The number of ova palpated in mid-vitellogenesis was greater in the high-intake group than in the low-intake group (one-way ANCOVA with number of palpated ova as the dependent variable, treatment as the factor and SVL as the covariate, $F 1,34=9.04, P<0.005)$. The divergence was even greater at ovulation $(F 1,33=10.68, P<0.0025$; see Fig. 4). The SVL-adjusted numbers of palpated 
ova were, respectively, $7.1 \pm 2.46$ (high-intake group) and $5.14 \pm 1.89$ (low-intake group) in midvitellogenesis and $6.67 \pm 1.82$ and $5.03 \pm 1.47$ at the time of ovulation. A regression analysis pooling data from the two treatments confirmed that food intake during vitellogenesis influenced the number of ova at ovulation $(r=0.42, r 2=0.17, n=36, P=0.01)$.

In addition to food intake, female SVL and early body condition are known to influence fecundity in aspic vipers (Bonnet, Naulleau, Shine et al., 2001). Thus all three of these variables were included in a multiple regression analysis. As predicted, the highest proportion of fecundity variation in our dataset was explained by a model including all three predictor variables $\left(r^{2}=0.41\right.$; see Table 1). When univariate regression analyses were conducted separately on data from the two treatment groups, however, strong differences were evident. Early body condition significantly affected fecundity in the high-intake females $\left(r=0.71, r^{2}=0.50, n=17, P<0.02\right)$ but not in the low-intake group $(r=0.34, n=19, P=0.56)$. Similarly, fecundity increased with maternal SVL in the high-intake animals $\left(r=0.56, r^{2}=0.31, n=17, P=0.018\right)$, but not in the low-intake group $(r=0.33, n=19, P=$ 0.16). As a consequence, the combination of these two factors in a multiple regression explained a significant fraction of fecundity variation among the high-intake females $\left(r=0.69, r^{2}=0.46, n=17, P\right.$ $=0.01)$, but not among the low-intake snakes $\left(r=0.34, r^{2}=0.11, n=19, P=0.56\right)$.

\section{DISCUSSION}

The experimental data from this study strongly support the conclusions of a recent descriptive study by Bonnet, Naulleau, Shine et al. (200 1) on free-ranging snakes. That is, the number of ova (litter size) produced by a female aspic viper is influenced not only by her body condition at the beginning of the year in which she will reproduce, but also by the amount of food that she consumes during the period of vitellogenesis. The body size of the female snake also plays a role in determining fecundity, probably because a larger female has more abdominal space in which to accommodate the litter (Saint Girons, 1957a). Thus, litter size in a female $V$. aspis is affected in a complex way by her body size, her pre-existing energy stores, and her food intake in the weeks immediately before ovulation.

Experiments on the influence of energy input on reproductive output have provided valuable information in many vertebrate species (Arcese \& Smith, 1988; Bolton, Momaghan \& Houston, 1993; Monaghan \& Nager, 1997 and references therein) including snakes (Ford \& Seigel, 1989, 1994; Seigel \& Ford, 1991, 1992, 2001; Gregory \& Skebo, 1998). However, in a capital breeding species, the levels of pre-vitellogenic maternal reserves largely determine reproductive output (Bonnet, Naulleau, Shine et al., 2001). The possible effects of additional income energy (i.e. through manipulation of the diet) should be framed within this context. Unfortunately, quantitative data on the processes involved in mobilization of body reserves for follicular growth are only available for $V$. aspis. Both empirical and experimental works on this species have shown that a peak in 17-6 oestradiol level triggers body reserve mobilization and yolk deposition (Bonnet, Naulleau \& Mauget, 1994; Bonnet, 1996). In the absence of equivalent data on the hormonal control of vitellogenesis in other species, interspecific comparisons would be premature.

The female's 'decision' as to whether or not to reproduce seems to be determined primarily by her initial body condition, making $V$. aspis a typical 'capital breeder' in this respect (Naulleau \& Bonnet, 1996). However, the two 'cancellations' (females that initiated but did not maintain vitellogenesis) suggest that food intake during vitellogenesis might also play a role in this early 'decision'. That is, a female close to the energy-store threshold for reproduction may begin vitellogenesis, but abandon the process unless she obtains prey relatively soon. Resorption of follicles is probably adaptive, enabling the animal to recover resources if reproduction does not proceed (Blackburn, 1998).

Our experimental manipulation of food intake significantly modified not only the amount of 
maternal mass that was gained, but also the number of ova that were ovulated (and hence, litter size). Female body size and initial body condition also affected fecundity in aspic vipers, as they do in other species of snakes (Seigel \& Ford, 1987). Pooling data from the two treatment groups allowed us to detect significant influences of maternal SVL, fat stores and food intake on fecundity. However, conducting the analyses separately revealed that the effects of body reserves and body length were only statistically significant in the high-intake group. The differing importance ofbody length as an influence on fecundity may reflect the fact that total abdominal space (and thus, female body length) became a significant constraint on fecundity in the high-intake snakes. If so, we would expect to see larger litters in larger females than in smaller snakes. In contrast, because snakes in the lowintake treatment group produced small litters fitting easily within the females' bodies, maternal body size was not a constraint (nor a correlate) of the variation in fecundity among these animals.

The differing role of pre-existing energy reserves is less easy to explain, but may simply reflect that the variation in food intake (and thus, the number of developing ova) among the highintake females was higher than that in the low-intake snakes. Data collected by Saint Girons \& Naulleau (1981) demonstrate that in female aspic vipers the mass of abdominal fat bodies is correlated with the number of growing follicles. Our results show that, after this initial phase, an exogenous source of energy will affect the number of ovulated eggs. The greater variation in food intake and reproductive traits might explain why correlates of reproductive output were detected more easily in the high-intake group than in the low-intake snakes.

Our study confirms that $V$. aspis is a typical capital breeder in some respects, notably in the 'decision' of whether or not to reproduce. Thus, capital stores (which reflect energy intake over long time periods) will ultimately determine reproductive frequencies in aspic vipers. In contrast, litter sizes will be determined not only by those pre-existing stores, but also by the female's foraging success in the weeks immediately before ovulation (Bonnet, Naulleau, Shine et al., 2001). This flexibility in energy allocation enables the snakes to adjust their reproductive investment relative to local resource levels and is consistent with field data (Lourdais et al., in press). Capital breeding is widespread among ectotherms (Doughty \& Shine, 1997; Bonnet, Bradshaw \& Shine, 1998) and may be particularly advantageous in situations of strong inter-annual fluctuations in food availability (Calow, 1979). Vipera aspis is a sit-and-wait predator which feeds mainly on rodents, especially voles Microtus arvalis, that show dramatic fluctuations in population density (Delattre et al., 1992; Lourdais et al., in press). In a situation where prey densities are unpredictable from year to year, a female aspic viper directly benefits from being able to:

(1) reproduce successfully without having to depend upon food intake during the reproductive year. In a year when prey is scarce, a female relying upon 'income' might fail to breed successfully, and either waste resources already invested or threaten her own survival. 'Capital breeding' provides a mechanism for a temporal dissociation between feeding and breeding.

(2) modify her reproductive output in a flexible fashion depending upon current levels of prey availability. Essentially, this flexibility allows the female to manipulate energy investment into reproduction and hence take advantage of 'good' years by producing more offspring than would have been expected from the long-term average levels of prey availability in her habitat. Thus, although many aspects of reproduction in aspic vipers are driven by 'capital' stores, some degree of reliance on 'income' may help to fine-tune reproductive expenditure to food intake during the critical phase of egg production.

\section{Acknowledgements}

We thank Gwénael Beauplet for helpful comments on the manuscript. Financial support was provided by the Conseil Régional de Poitou-Charentes, Conseil Général des Deux Sèvres, the Centre National de la Recherche Scientifique (France). Manuscript preparation was supported by the Australian Research 
Council. We thank Professor Oumid Popoye and Mr Celestin Le khobrato for helping in snake collection and the construction of the electrical fence to impede feral cat predation. Mr Dujardin helped to solve many technical problems.

\section{REFERENCES}

Arcese, C. D. \& Smith, J. N. M. (1988). Effects of population density and supplemental food on reproduction in song sparrow. J. Anim. Ecol. 57: 119-136.

Blackburn, D. G. (1998). Resorption of oviductal eggs and embryos in squamates. Herpetol. J. 8: 65-71.

Bolton, M., Monaghan, P. \& Houston, C. D. (1993). Proximate determination of clutch size in lesser blackbacked gulls: the roles of food supply and body condition. Can. J. Zool. 71: 273- 279.

Bonnet, X. (1996). Gestion des r'eserves corporelles et strat'egie de reproduction chez Vipera aspis. PhD thesis, Universit'e Claude Bernard, Lyons I.

Bonnet, X., Bradshaw, S. D. \& Shine, R. (1998). Capital versus income breeding: an ectothemic perspective. Oikos 83: 333-341.

Bonnet, X. \& Naulleau, G. (1996). Catchability in snakes: consequences on breeding frequency estimates. Can. J. Zool. 74:233-239.

Bonnet, X., Naulleau, G. \& Lourdais, O. (2002). The benefits of complementary techniques: using capturerecapture and physiological approaches to understand costs of reproduction in the asp viper. In Biology of the vipers. Schuett, G. W.,

Hoggren, M. \& Greene, H. W. (Eds). Traverse City, MI: Biological Science Press. (In press.)

Bonnet, X., Naulleau, G., Lourdais, O. \& Vacher-Vallas, M. (1999). Growth in the asp viper (Vipera aspis L.): insights from a long term field study. In Current studies in herpetology: 63-69. Miaud, C. \& Guyetant, R. (Eds). France: Le bourget du Lac.

Bonnet, X., Naulleau, G. \& Mauget, R. (1994). The influence of body condition on 17-P estradiol levels in relation to vitellogenesis in female Vipera aspis (Reptilia, Viperidae). Gen. Comp. Endocrinol. 93: 424-437.

Bonnet, X., Naulleau, G., Shine, R. \& Lourdais, O. (2000). What is the appropriate time scale for measuring costs of reproduction in a capital breeder? Evol. Ecol. 13: 485-497.

Bonnet, X., Naulleau, G., Shine, R. \& Lourdais, O. (2001). Short-term vs long-term effects of food intake on reproductive output in a viviparous snake (Vipera aspis). Oikos 92: 297-308.

Calow, P. (1979). The cost of reproduction - a physiological approach. Biol. Rev. 54: 23-40.

Delattre, P., Giraudoux, P., Baudry, J., Truchetet, D., Musard, P., Toussaint, M., Stahl, P., Poulle, M. L., Artois, M., Damange, J. P. \& Quere, J. P. (1992). Land use patterns and types of common vole (Microtus arvalis) population kinetics. Agric. Ecosyst. Environ. 3: 153-169.

Doughty, P. \& Shine, R. (1997). Detecting life history trade-offs: measuring energy stores in 'capital' breeders reveals costs of reproduction. Oecologia (Berl.) 110: 508-513.

Drent, R. H. \& Daan, S. (1980). The prudent parent: energetic adjustments in avian breeding. Ardea 68: 225252.

Fitch, H. S. (1987). Collecting and life-history techniques. In Snakes: ecology and evolutionary biology: 143-164. Seigel, R. A., Collins, J. T. \& Novak, S. S. (Eds). New York: Macmillan.

Ford, N. B. \& Seigel, R. A. (1989). Phenotypic plasticity in reproductive traits: evidence from a viviparous snake. Ecology 70:1768-1774.

Ford, N. B. \& Seigel, R. A. (1994). Phenotypic plasticity: implication for captive breeding and conservation programs. In Captive management and conservation of amphibians and reptiles: 175-182. Murphy, J. B., Collins, J. T. \& Adler, K. (Eds). Oxford, OH: Society for the Study of Amphibians and Reptiles.

Gregory, P. T. \& Skebo, K. M. (1998). Tradeoffs between reproductive traits and the influence of food intake during pregnancy in the garter snake. Thamnophis elegans. Am. Nat. 151:477-486.

Jayne, B. C. \& Bennett, A. F. (1990). Selection on locomotor performance capacity in a natural population of garter snakes. Evolution 44: 1204-1229.

Lourdais, O., Bonnet, X., Shine, R., DeNardo, D., Naulleau, G. \& Guillon, M. (In press). Capital-breeding and reproductive effort in a variable environment: a longitudinal study of a viviparous snake. J. Anim. Ecol.

Marti, D. M. (1990). Sex and dimorphism in the barn owl, a test of mate choice. Auk 107: 246-254.

Monaghan, P. \& Nager. R. N. (1997). Why don't birds lay more eggs? Trends Ecol. Evol. 7: 270-274. 
M'endez-De la Cruz, F. R., Guillette, L. J. Jr \& Villagran-Santa Cruz, M. (1993). Differential atresia of ovarian follicles and its effects on the clutch size of two populations of the viviparous lizard Sceloporus mucronatus. Funct. Ecol. 7: 535-540.

Naulleau, G. (1981). D'etermination des p'eriodes de l'ovulation chez Vipera aspis et Vipera berus dans l'ouest de la France, 'etudi'ee par radiographie. Bull. Soc. Sci. Nat. Ouest Fr. 3: 151-153.

Naulleau, G. \& Bonnet, X. (1996). Body condition threshold for breeding in a viviparous snake. Oecologia (Berl.) 107: 301-306.

Naulleau, G., Bonnet, X., Vacher-Vallas, M., Shine, R. \& Lourdais, O. (1999). Does less-than-annual production of offspring by female vipers (Vipera aspis) mean less-than-annual mating? J. Herpetol. 33: 688-691.

Saint Girons, H. (1949). Les moeurs nuptiales de la Vip`ere aspic. Terre Vie 96: 110-113. 


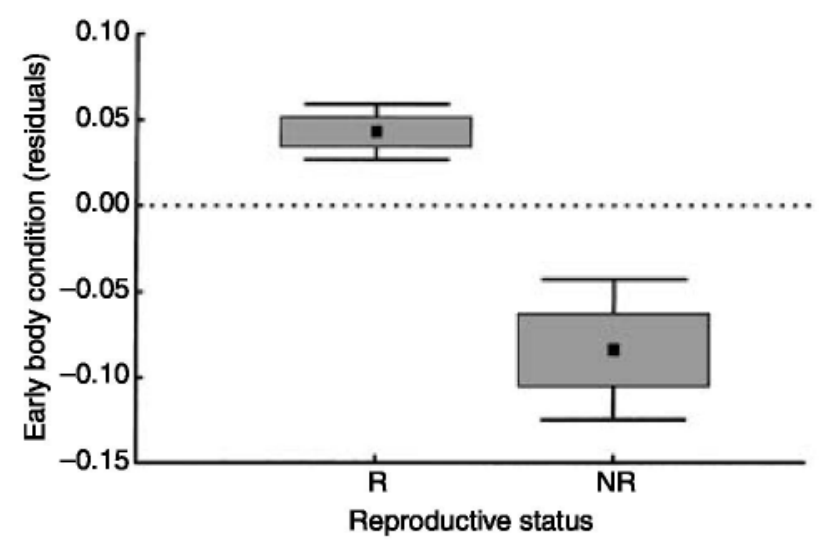

Fig. 1. Body condition of female vipers Vipera aspis at the onset of the experiment, as measured by residual scores from the linear regression of log-transformed body mass vs log-transformed SVL. R, reproductive; NR, non-reproductive; black square, mean value; grey square, standard deviation; error bar, 1.96 SD.

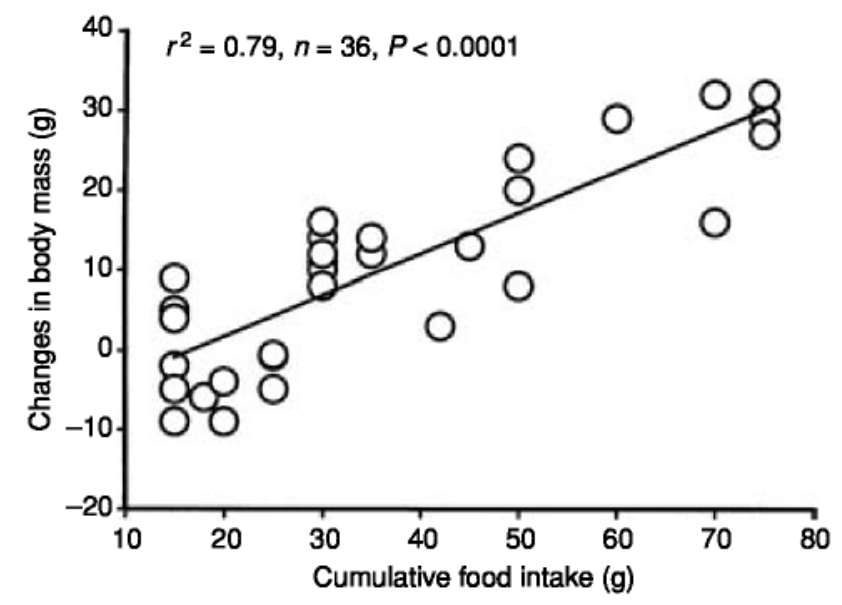

Fig. 2. The relationship between total food intake (g) of 36 female aspic vipers Vipera aspis and change in body mass (g) during the experiment. Each point represents an individual snake. The two treatment groups were pooled for this analysis. 


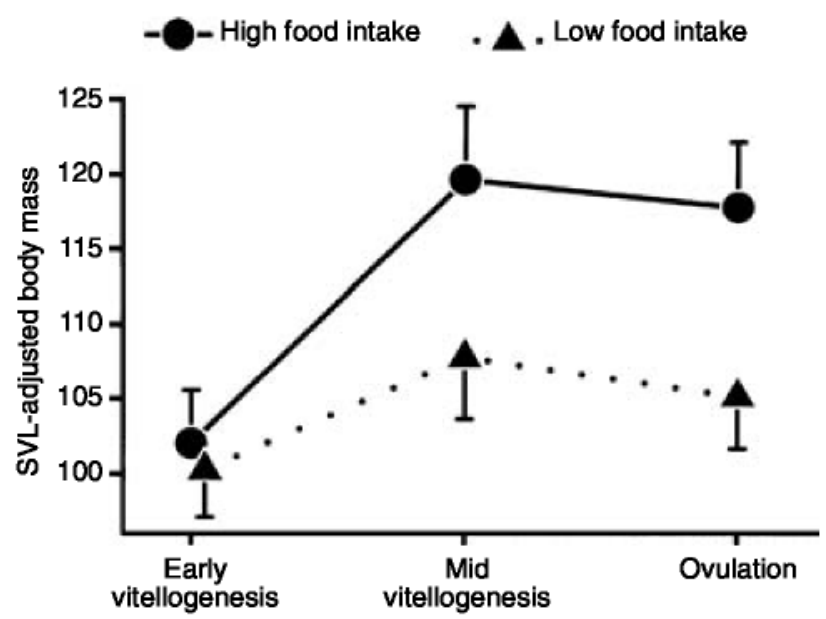

Fig. 3. Influence of experimental treatment (diet) on changes in body mass of female vipers Vipera aspis at three times during the experiment. Circles, high food intake group; triangles, low food intake group; SVL, snout-vent length.

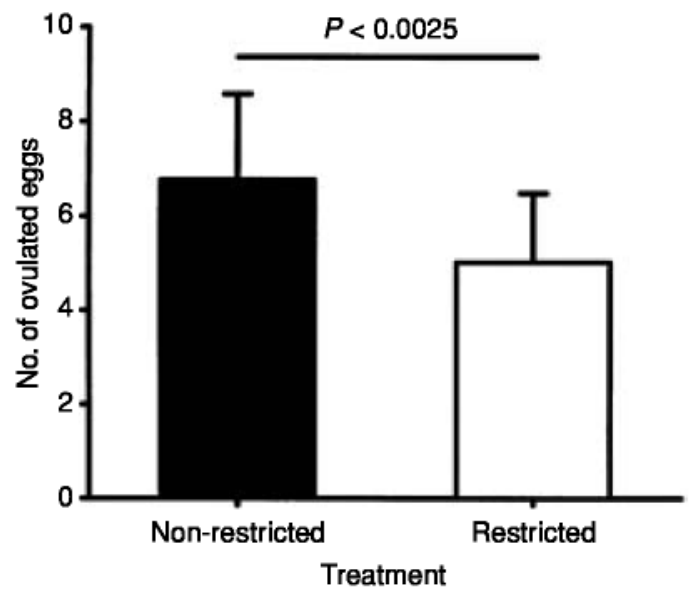

Fig. 4. Effects of experimental manipulation of food intake on the number of ova ovulated by aspic vipers Vipera aspis. Error bars, SD.

Table 1. The effects of maternal body size (SVL), food intake during vitellogenesis (FOOD), and maternal body condition $(\mathrm{BC})$ before vitellogenesis (residual scores from log-transformed mass vs SVL) on litter size of female aspic vipers Vipera aspis. Results shown are from a multiple regression carried out on the entire data set (i.e. including female vipers from both treatment groups). The highest proportion of fecundity variance was explained by a model that included all three independent variables. Multiple

\begin{tabular}{lllll}
\hline & BETA & Partial correlation & Semi-partial & $P$-value \\
\hline SVL & 0.36 & 0.36 & 0.42 & 0.012 \\
FOOD & 0.39 & 0.38 & 0.44 & 0.008 \\
BC & 0.30 & 0.30 & 0.36 & 0.033 \\
\hline
\end{tabular}

